\title{
LAS FRONTERAS DEL ISTMO CENTROAMERICANO: UNA GEOPOLÍTICA DE LARGA DURACIÓN*
}

\author{
Por \\ Alain Musset**
}

RESUMEN

Contrariamente a muchas ideas generadas, las fronteras que dividen a América Central en siete Estados diferentes, no tienen por origen las fracturas políticas provocadas por las guerras de independencia del principio del siglo XIX. Ellas son el resultado de un largo proceso de elaboración y de consolidación, nacido en el momento de la conquista española, y que aún no ha terminado. El fin de este estudio es volver a colocar a lo largo del tiempo una geopolítica muy contemporánea para, de esta menra, entender mejor la formación de los territorios y de las naciones que comparten el istmo. Bajo esta perspectiva, la frontera ya no debe ser percibida como una línea sencilla, sino como un espacio cuya extensión puede evolucionar según la época y los medios de comunicación disponibles para facilitar la integración regional de los países centroamericanos (principalmente la panamericana o CA-1). Marginadas por mucho tiempo por razones económicas y políticas, las zonas fronterizas pueden convertirse en nuevos ejes de desarrollo en un espacio marcado por la presencia de numerosos enclaves y por la debilidad de los flujos interregionales.

\begin{abstract}
Contrary to popular opinion, the boundaries which separate Central America into seven different countries, do not have their origin in the political divisions caused by the wars for independence fought at the beginning of the nineteenth century. They are the result of a long process of labor and consolidation which began with the Spanish Conquest, and is still going on. The purpose of this study is to place a very contemporary geopolitical view along a timeline, in order to better understand the formation of the territories and the nations that share the isthmus. From this perspective, the border should not now be perceived as a single line, but as a space whose extension may evolve according to the era and the means of communication available to facilitate the regional integration of the Central American countries (principally the Pan-American or CA-1). Long overlooked, for economic and political reasons, the border zones may be converted into new avenues of development in an area marked by the presence of numerous enclaves and by the weakness of flows between regions.
\end{abstract}

\section{INTRODUCCIÓN: UNA SITUACIÓN GEOPOLÍTICA}

* Traducido del francés por Danielle Wynants.

** Geógrafo, Universidad de París X, Instituto Universitario de Francia. 


\section{PARADÓJICA}

El 14 de julio de 1969, una guerra relámpago iniciada entre Honduras y El Salvador, alimentó la crónica de grandes periódicos del mundo entero. Inducidos después de un partido de futbol que tomó mal cariz, los combates causaron numerosas víctimas en ambas partes de la frontera. Este evento, puesto en evidencia por la comunidad internacional, sirvió para demostrar lo absurdo de algunos conflictos locales (presentados como típicamente latinoamericanos) que podían encender a una región entera bajo fútiles pretextos. Los periodistas de la época se rehusaron entonces a ver que las causas de ese conflicto rebasaban ampliamente el marco estrecho de un estadio de futbol, para inscribirse en un contexto económico y político tenso (decenas de miles de campesinos salvadoreños habían ocupado ilegalmente las tierras vírgenes localizadas del lado hondureño de la frontera), y en una historia antigua pero que a menudo se conocía mal.

En efecto, los siete Estados que comparten el istmo centroamericano (alrededor de $540000 \mathrm{~km}^{2}$ ), ofrecen la particularidad de poseer una cultura y un idioma comunes (excepto Belice, antigua posesión de la corona inglesa).

A nivel regional, Guatemala, Honduras y Nicaragua, que sobrepasan los $100000 \mathrm{~km}^{2}$, juegan un papel de gigantes. A su lado, Belice y El Salvador, que apenas alcanzan $20000 \mathrm{~km}^{2}$, parecen minúsculos (figura1).

Esa fragmentación del istmo puede parecer asombrosa, pero corresponde a datos geopolíticos sólidamente arraigados en el espacio y en las mentalidades centroamericanas. Contrariamente a las ideas preconcebidas, las fronteras no fueron arbitrariamente fijadas al principio del siglo XIX después del retiro forzoso de los españoles, sino que corresponden a divisiones operadas en el curso de la época colonial por los mismos conquistadores, deseosos de asegurarse un "espacio de vida", a la vez coherente, fácil de explotar y para defenderse de la codicia de sus vecinos: indios rebeldes, ingleses audaces o competidores que, como ellos, venían de la Península Ibérica.

Pero si las fronteras más o menos bien delimitadas son antiguas, no es el caso de las naciones. De modo paradógico, los Estados procedentes de las guerras de independencia habían heredado un territorio, mas no una población homogénea que podía reconocerse en un ideal común. Cuando en Europa los pueblos en busca de espacio buscaron dotarse de fronteras reconocidas, en América Central la historia conoció un curso inverso. Desde el origen, las élites urbanas encarnaron el nuevo modelo del Estado independiente. Formadas en el molde ideológico del mundo colonial, 
utilizaron fronteras preexistentes para tratar de justificar la existencia de diferentes naciones que abolirían las antiguas fracturas étnicas y sociales para el provecho de un patriotismo exacerbado. Las divisiones internas y verticales - es decir jerárquicas-, de la sociedad centroamericana, debían ser reemplazadas por divisiones externas y horizontales, es decir; espaciales y territoriales.

Ese contexto geopolítico particular, hace de América Central un verdadero caso de estudio, que se distingue a la vez de su modelo europeo y de la situación que podemos encontrar en otros espacios antiguamente colonizados como África. El fracaso recurrente de las tentativas de unión política en la región del istmo, enseña que de alguna manera, el modelo del Estado-nación impuesto por los dirigentes del siglo XIX, pudo conseguir una legitimidad verdadera, fundada al mismo tiempo sobre el encauzamiento de las minorías étnicas (en el interior de los Estados), y sobre un discurso nacionalista y a veces xenófobo que terminó por penetrar en todos los estratos de la sociedad.

Al principio de los años noventa, una encuesta realizada bajo la iniciativa de la Universidad de Pittsburgh, mostró que el apego al concepto de unidad centroamericana era muy variable según los países, los estratos sociales interrogados y los temas abordados (la moneda única, el Parlamento Centroamericano, el Mercado Común). Así, mientras 97\% de los salvadoreños reclamaban una integración regional más fuerte, esa proporción caía a 59\% en Panamá. Del mismo modo, cuando en Honduras y en El Salvador, más de $70 \%$ de las personas interrogadas se declaraban de acuerdo para hacer de América Central un solo país, en Panamá y Costa Rica prevalecía ampliamente la oposición con $69 \%$ y $83 \%$ de opiniones desfavorables respectivamente. Barrera ideológica, fantasma político o pasarela económica entre los Estados demasiado parecidos para aceptar unirse, la frontera se queda, pues, en el centro de un proceso largo de integración territorial que no podrá concretarse y difundirse sino a partir de esos márgenes fronterizos, a la vez abandonados sobre el plano económico y sacralizados sobre el plano simbólico, por países en busca de su propia identidad.

\section{EL MOSAICO CENTROAMERICANO}

Sin sucumbir al determinismo, podemos explicar esas divisiones políticas por la extrema fragmentación de las unidades físicas y humanas. Tan sólo en El Salvador, por ejemplo - un país que rebasa apenas los $21000 \mathrm{~km}^{2}$ de territorio-, se han podido determinar unas 60 unidades morfologicas (alternación de cuencas y de macizos). Aunque en general las distancias 


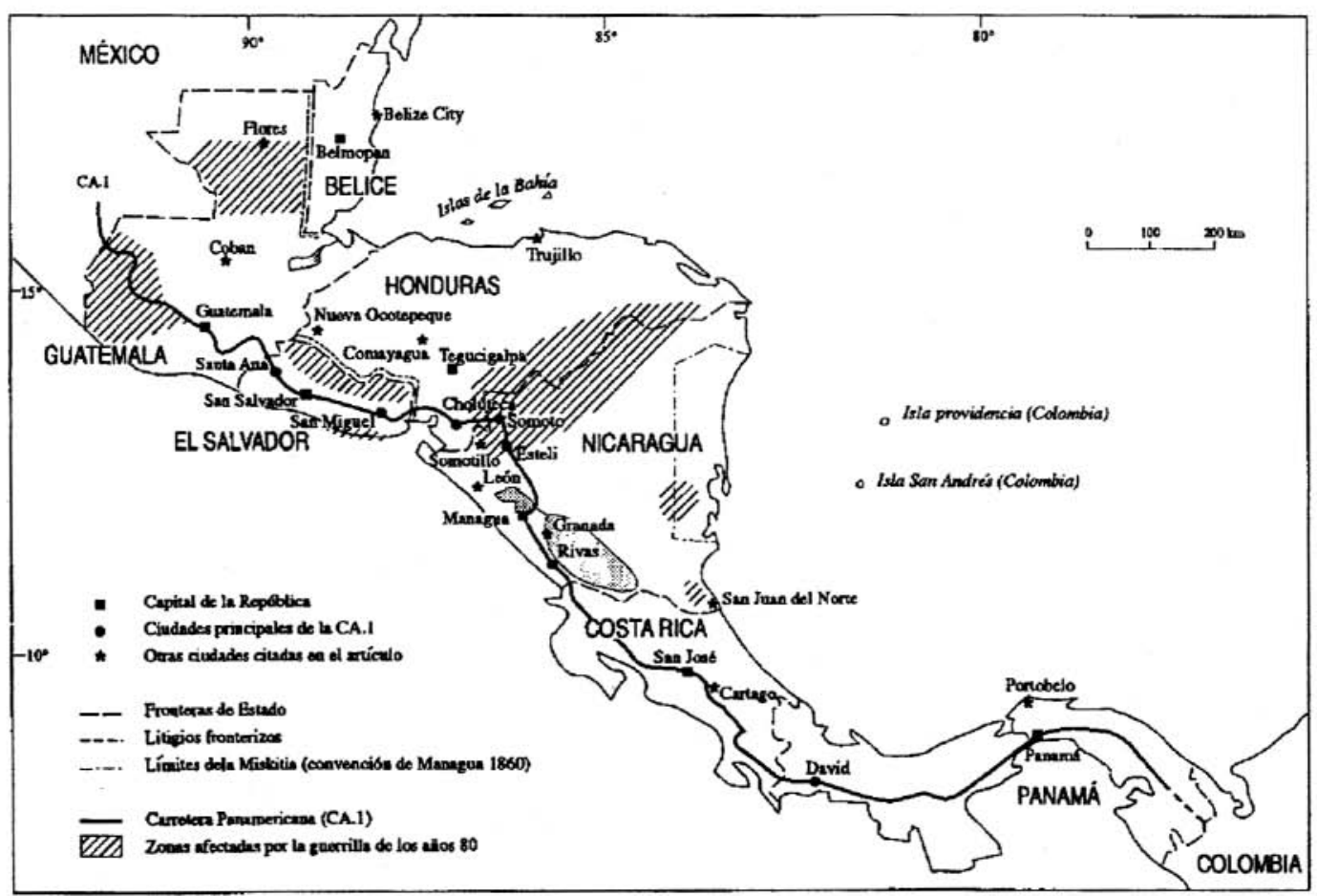

Figura 1. Las fronteras del istmo centroamericano. 
son cortas, el medio ambiente natural muy accidentado contribuye al comportamiento y a la fragmentación del espacio. Asimismo, los desniveles abruptos acentúan los contrastes climáticos en una zona de estructura compleja, marcada por direcciones tectónicas dominantes. Entre los macizos montañosos, fracturas y zanjas de hundimiento cortan el relieve, matizado por la multitud de conos volcánicos. Esa disposición ha limitado lo largo y el caudal mediano de los ríos que son de tamaño mediocre; el perfíl accidentado y su régimen de mucho contraste (entre la estación seca y la estación de lluvias), no permiten utilizarlos más que muy escasamente como vía de comunicación. El río más largo, el Usumacinta, es navegable para barcos de poco tonelaje en una distancia de alrededor de $530 \mathrm{~km}$, pero desafortunadamente pertenece en su mayoría a México. El río Motagua, enteramente guatemalteco, tiene un cause largo de $400 \mathrm{~km}$ y profundo de 5 m máximo que permite el tránsito de pequeñas embarcaciones sobre la mitad de su curso.

Por mucho tiempo, los ríos Dulce (Guatemala), San Juan (Nicaragua) y Chagres (Panamá), permitieron a pequeñas embarcaciones penetrar al interior de las tierras, pero hoy el tráfico es muy reducido y puramente local. ${ }^{1}$ Lejos de contribuir a desenclavar el territorio centroamericano, los ríos son, pues, obstáculos que hay que atravesar o rodear; perpendiculares al eje general del istmo, acentúan el comportamiento generalizado que favorece el pliegue sobre sí mismo y la ausencia de relaciones entre las diferentes regiones.

A excepción de El Salvador - que no posee costa en el Atlántico-, cada Estado centroamericano posee la misma estructura: una llanura litoral estrecha caracteriza la vertiente del Pacífico, dominada por las escarpas de las cordilleras centrales. En el centro, la cuenca del río Chagres sirve hoy en día para alimentar el lago artificial de Gatún, concebido para permitir el funcionamiento de las esclusas del canal de Panamá. Hay tierras altas, sierras o altas planicies, como las del occidente guatemalteco, caracterizadas por alturas superiores a $1000 \mathrm{~m}$. Allí, a pesar de un relieve muy dividido en compartimientos que hacen las comunicaciones difíciles, un clima templado y suelos fértiles han favorecido el asentamiento. En el noroeste se encuentran tierras bajas en la zona del Caribe, cubiertas de la selva tropical húmeda. Mal enlazadas a las otras regiones, por mucho tiempo sirvieron como refugio para los indios insumisos, como los miskitos de Nicaragua - que fueron colonizados por las grandes compañías bananeras desde el fin del siglo XIX-. Esta costa, con un clima dicífil, fue

1 La cuenca del río Chagres sirve hoy en día para alimentar el lago artificial de Gatún, concebido para permitir el funcionamiento de las esclusas del canal de Panamá. 
por mucho tiempo ignorada por los españoles, que prefirieron instalarse sobre las alturas y los litorales del Pacífico, zonas menos pluviosas y más sanas, según los cánones de la escuela hipocrática en vigor en el curso de la época colonial. ${ }^{2}$

De hecho, los conquistadores decidieron establecerse en el istmo centroamericano desde su arribo a América: su presencia durante tres siglos fue la que permitió unificar en parte territorios hasta entonces divididos en una multitud de pequeños reinos, provincias y jefaturas. Las primeras expediciones datan de 1506, cuando Alonso de Ojeda y Diego de Nicuesa empezaron a explorar el golfo de Darién. Después de ellos, los conquistadores se sucedieron en busca de riquezas más grandes aún que las que Cortés se había adueñado penetrando en las ruinas de Tenochtitlan. Sus lugartenientes, Cristóbal de Olid y Pedro de Alvarado, tomaron posesión de Honduras y de Guatemala, mientras que Francisco Hernández de Córdoba descubría el gran lago de Nicaragua (Cocibolca) y fundaba sobre sus orillas la ciudad de Granada (1524). Como en toda América Latina, la ciudad era entonces la expresión misma de la conquista. Debía demarcar el territorio, fijar a la población y servir de base para futuras avanzadas hacia regiones aún desconocidas. En menos de un decenio, varios centros urbanos de primera importancia salieron a la luz, aunque algunos de ellos fueron luego desplazados por diversas razones (catástrofes naturales, ataques de indios o de piratas): Panamá en 1518, Cartago en 1522 y León, 1524, Trujillo, San Salvador y Guatemala en 1524. Gracias a ese grupo de fundaciones que demandarían el espacio centroamericano por mucho tiempo, la parte más grande del istmo fue sometida al poder de los españoles.

Contrariamente a lo sucedido en Perú y México, los conquistadores tuvieron poco interés en dominar las tierras descubiertas: el relieve accidentado de las montañas, la densa selva, el clima caliente y húmedo de las tierras bajas, hacían difíciles su proceso y su establecimiento. La ausencia de un gran imperio como el de los aztecas o de los incas, cuyas estructuras políticas hubieran podido utilizarse, les entorpeció para imponer su ley, pues poblaciones hostiles resistieron durante mucho tiempo.

A pesar de numerosas expediciones militares, los últimos mayas del reino de Tayasal, refugiados sobre la isla del lago Petén-Itzá (Guatemala), no se rindieron sino hasta 1697.

2 Ese fraccionamiento del espacio natural del istmo centroamericano, corresponde a una gran diversidad de áreas culturales. Incluso los mayas, contrariamente a lo que se ha pensado por mucho tiempo, nunca han formado un pueblo unido. Lo que se llama de manera impropia el "imperio maya", era una estructura política floja, compuesta de una serie de ciudades-Estados que mantenían entre ellos relaciones a menudo conflictivas. 
Por otra parte, América Central no disponía de grandes reservas de metales preciosos. La única riqueza era la tierra, una tierra que había que trabajar. Las ganancias eran pocas, comparadas con las de los propietarios de minas de Potosí, Taxco o Zacatecas. La población española de esas regiones estaba diseminada. Sin embargo, se trataba de un lugar estratégico: en 1513, Balboa atravesó el istmo de Panamá y descubrió el oceáno Pacífico. Cinco años más tarde, Pedrarias Dávila fundó la ciudad de Panamá, que serviría de base para Pizarro en su conquista de Perú. Se creó entonces un eje mayor entre el mar del Norte (el Atlántico) y el mar del Sur (el Pacífico), por donde pasaban todas las riquezas del antiguo imperio inca.

Sobre las tierras abandonadas por los indígenas, los conquistadores se repartieron vastos dominios que limitaron la densificación y el desarrollo del espacio rural. En oposición a la población indígena, que consagraba lo esencial de su trabajo a una agricultura de subsistencia, se encontraban ya grandes explotaciones dirigidas por españoles que se dedicaban a una agricultura especulativa o una cría extensiva; tal es el caso de las ricas llanuras de trigo de la cuenca de Cartago en Costa Rica. Hasta el final de la época colonial, e incluso poco después se puede decir que los campos quedaron en gran parte en manos de los índigenas (subpoblados, subequipados y dependientes de los centros urbanos que monopolizaban lo esencial de las actividades y de las riquezas).

Sin embargo, las ciudades no desempeñaban verdaderamente el papel motor y su tamaño era mediocre. A finales del siglo XVI, la ciudad de Cartago, capital de la provincia de Costa Rica, alojaba a unas 80 familias de españoles (aproximadamente 400 personas). A la víspera de la independencia, su población rebasaba difícilmente los 8000 habitantes, de los cuales 600 eran españoles y criollos. En la misma época, Granada, capital de la provincia de Nicaragua, tenía un tamaño comparable. Con casi 12000 habitantes, San Salvador era entonces una de las ciudades más pobladas de la región (superada por Guatemala, sede de la capitanía con 25000 habitantes). Centros administrativos o grandes burgos rurales, cuya riqueza estaba fundada sobre la agricultura local, esas ciudades no tenían más que una influencia limitada por la organización regional, que poco favoreció los intercambios, y que permitió el desarrollo de un espíritu de campanario particularmente vivo en las élites urbanas. Estas situaciones dieron origen a los conflictos previos a las guerras de independencia y que provocaron el desmembramiento de la federación centroamericana.

Sobre las costas de clima caliente y húmedo, los puertos más importantes apenas si eran ciudades. Trujillo, que por mucho tiempo fue la puerta de entrada principal de Honduras, contaba únicamente con 20 familias de 
españoles en 1594. Hasta su abandono definitivo, en 1596, a consecuencia de los ataques de Drake, Nombre de Dios era habitada no más de dos meses al año, cuando la flota descansaba. En un mundo compuesto por pequeñas células autónomas, jugaron, de cualquier modo, un papel importante, ya que abrían la vida regional sobre el exterior, mantenían el contacto con las metrópolis y organizaban los flujos intercontinentales, que eran la columna vertebral del imperio español. Colocados sobre el trayecto de la carretera de las Indias, Panamá y Porto Belo gozaban de una situación privilegiada y formaban el único eje fuerte en la nebulosa centroamericana.

Hasta la mitad del siglo XVII, el conjunto portuario Nombre de DiosPorto Belo, representó más o menos dos terceras partes de los intercambios entre la América española y Europa. Esa vocación precoz fue el origen de un corte, aún sensible hoy en día, en la estructura económica, política y social de América Central -corte materializado por el canal interoceánico, terminado por los Estados Unidos en 1914, y que será definitivamente devuelto a las autoridades panameñas hasta el final del año 1999.

Desde la segunda mitad del siglo XVI, esas riquezas en tránsito atrajeron a los piratas y a los corsarios, cuyas audaces incursiones sembraban el pavor en medio de las poblaciones españolas. ${ }^{3}$

En el curso del siglo XVII, la guerra se volvió más convencional. Numerosos aventureros continuaron saqueando las riquezas del nuevo mundo. Sin embargo, los Estados europeros quisieron hacerse de un verdadero imperio de ultramar a costa de la América ibérica. De esta manera, leñadores ingleses se establecieron en Belice - destinado a ser la Honduras Británica hasta su independencia en 1973 - y resistieron todos los ataques llevados por los españoles. En 1862, los mexicanos reconocieron oficialmente la presencia inglesa, pero hubo que esperar hasta 1893 para fijar las fronteras entre ambas partes. Otros colonos ingleses se instalaron más al sur, sobre la costa atlántica de Nicaragua, favoreciendo la creación de un reino miskito aliado a la corona inglesa. En 1841, los británicos impusieron al gobierno nicaragüense la presencia de un protectorado sobre todo el litoral atlántico del país: desde Honduras hasta la desembocadura del río San Juan.

Cuando la influencia inglesa empezó a declinar a favor de los Estados Unidos - hacia la mitad del siglo XIX-, ese vasto territorio fue incorporado a la joven república centroamericana. Sin embargo, la Casa Blanca obtuvo para sus protegidos un estatuto especial, confirmado en 1860 por

3 Las expediciones llevadas por Hawkins en 1562, luego por Drake a partir de 1573, devastaron toda la zona del Caribe. En 1671, Henry Morgan redujo en cenizas la ciudad de Panamá, cuyo sitio fue desplazado dos años más tarde. 
la creación de una "reserva miskita", disfrutando de un cierto grado de autonomía frente al gobierno de Managua. ${ }^{4}$

Esta larga historia explica la ventaja tomada por la lucha armada entre sandinistas y los indios de la Mosquitia en los años ochenta, cuando los vencedores de Somoza rechazaron las reivindicaciones de la Misurasata, so pretexto que eran separatistas y contrarrevolucionarios.

En Honduras, con todo y que fueron relativamente salvados del apetito del ogro británico, los españoles tuvieron que pelear bastante para impedir a los anglosajones apoderarse de la costa del Atlántico, mal defendida por algunas avanzadas entre las cuales se encontraba el puerto de Trujillo, antigua capital de la provincia, antes de que Comayagua tomara su lugar, por razones a la vez estratégicas y sanitarias. ${ }^{6}$ Repetidas veces, sin embargo, los españoles tuvieron que retirarse de las zonas más expuestas a los ataques de sus enemigos. Fue precisamente el caso de las islas de la bahía (Utila, Guanaja y Roatán), que en el siglo XVII se volvieron un verdadero refugio para los corsarios y los piratas de origen inglés que habían podido atraer la simpatía de las poblaciones indígenas. La presencia británica ha dejado huellas durareras en la actual toponimia de ese pequeño archipiélago, ya que numerosos lugares llevan aún nombres de origen anglosajón: West End, Hatch Point, Sandy Bay o Coxen Hole (recientemente vuelto a bautizar Roatán por los hondureños).

Todas esas incursiones y esas intervenciones extranjeras contribuyeron pues, a acentuar el desmoronamiento político del istmo centroamericano. Pero la división del medio natural, las divisiones étnicas, la débil influencia de las ciudades españolas y la importancia de la penetración inglesa, luego norteamericana - en resumidas cuentas limitada en algunos enclaves políticos o económicos, tales como las grandes plantaciones de la United Fruit Company - no explican todo: las fronteras actuales de América Central se fundan en gran parte sobre antiguas líneas de fractura que separaban diferentes grupos de conquistadores de origen ibérico.

4 En la época de José Santos Zelaya (1893-1909), la anexión definitiva de la Mosquitia, —operación bautizada "reincorporación"- - fue decidida a fin de estimular el entusiasmo nacionalista de los ladinos de la costa del Pacífico.

5 Misurasata (miskitos, sumus, ramas, sandinistas, asla takanta): asociación indígena creada en 1979 para favorecer la cooperación entre diferentes grupos étnicos de la costa atlántica de Nicaragua. En miskito, asla takaranta significa "trabajar juntos".

6 El obispado fue transferido de Trujillo a la Nueva Valladolid de Comayagua en 1561. Como lo decían sus habitantes en una carta dirigida al rey en 1539: "Tiene los mejores pastos y yeguas y monte de toda la tierra y es tierra muy templada de un temple maravilloso ni muy caliente ni muy frío" (Archivo General de Indias, [Sevilla], Guatemala, 43, núm. 76). 


\section{LA GÉNESIS DE LAS FRONTERAS}

La imprecisión y la complejidad de las estructuras administrativas del mundo colonial español, no han hecho más que agravar la parcelación del mundo centroamericano. Hasta el final del periodo colonial, todas las tierras que baña el mar de las Antillas (islas y continente), dependían oficialmente del reino de la Nueva España salvo, claro está, los territorios que no pertenecían a la corona española. Esa pertenencia puramente formal a un mismo grupo, garantizaba una unidad aparente, pues nunca permitió a esos territorios dispares, desigualmente poblados, desarrollados e integrados al sistema colonial, constituirse en una gran región económica o política.

En realidad, América Central no era gobernada desde México, sino desde Guatemala, ciudad sede de la Capitanía General de Guatemala. Y también hay que precisar que el poder del capitán general no era plenamente ejercido sobre los territorios demasiado alejados de la capital: las autoridades locales disponían, de hecho, de una autonomía muy grande.

En cuanto a Panamá (la Castilla del Oro del siglo XVI), cuya vida económica estaba ligada a las minas de Potosí, dependía del continente sudamericano, es decir, del virrey de Perú, después de su creación en 1717, de la Nueva Granada.

Al principio del siglo XVIII, la Capitanía General estaba dividida en 32 provincias con estatuto jurídico y administrativo variable: cuatro "gobiernos" (Comayagua, Nicaragua, Costa Rica y Soconusco), nueve alcaldías mayores y 19 corregímenes. (Villacorta, 1942:87).

La carta intitulada El viejo México a la Nueva España, dibujada en 1702 por el francés Nicolas de Fer, nos da una representación geopolítica del conjunto centroamericano a la víspera del siglo XVIII (figura 2). A pesar de lo impreciso de ciertos trazos (la península de Nicoya, por ejemplo, está muy desvanecida por el cartógrafo), constatamos que las diferentes provincias españolas que dependían de la Audiencia de Guatemala están claramente representadas. El trazo de las fronteras administrativas, marcado por una línea de puntos, sería reutilizado en gran parte por los Estados independientes nacidos después del fraccionamiento de las Provincias Unidas de América Central. La provincia de El Salvador no aparece aún; Honduras se extiende hacia el Pacífico sobre una parte de Guatemala a lo largo de la costa, y la frontera entre Honduras y Nicaragua es casi idéntica a la que existe hoy. El brazo norte del río Coco no está en el mapa. Más al sur, la frontera entre Nicaragua y Costa Rica ya es la que sería fijada en el momento de la independencia de los dos países, mismo trazo que fuera modificado posteriormente en beneficio de los costarricenses, 


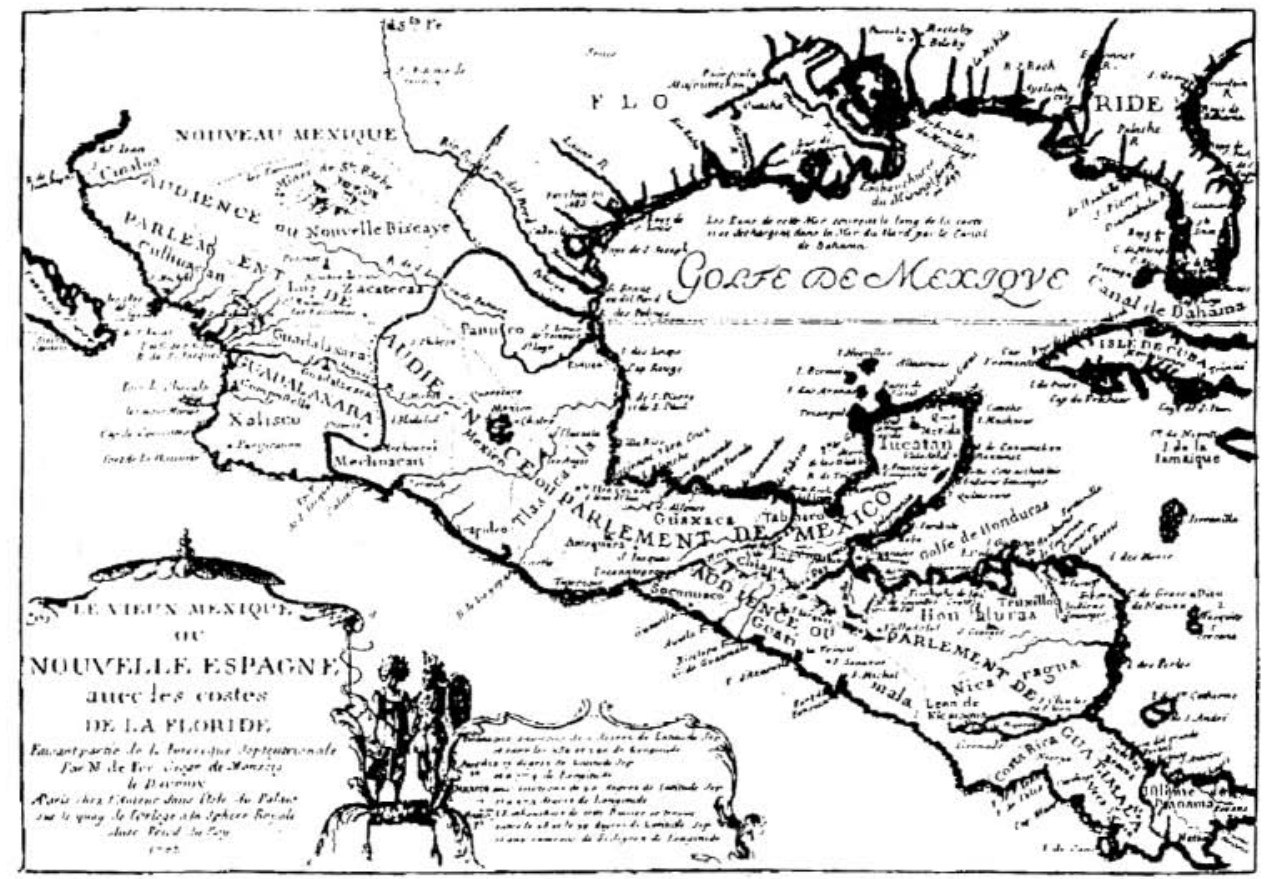

Figura 2. Mapa de Nicolás de Fer 1702.

Fuente: Biblioteca Nacional de París. 


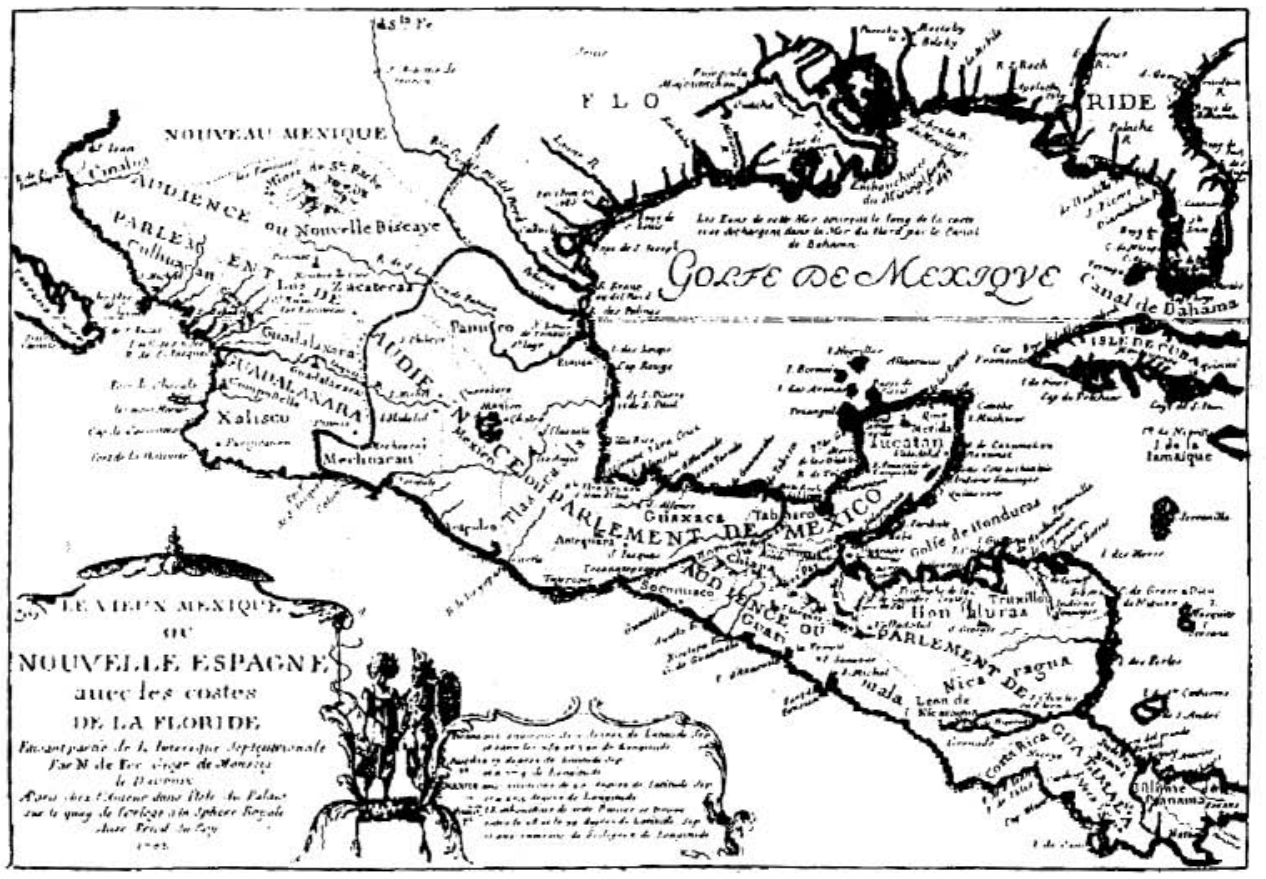

Figura 2. Mapa de Nicolás de Fer 1702.

Fuente: Biblioteca Nacional de París. 
en efecto, de fijar los límites de la provincia de Nicaragua, para prohibir su acceso a los españoles instalados más al norte, en la provincia de Honduras (más precisamente a los hombres de Pedro de Alvadado):

\begin{abstract}
Suplicamos a vuestra Magestad nos haga merced que por quanto esta gobernación no tiene limites señalados que vuestra magestad sea servido mandar que se entienda en los términos e limites desta gobernación desde golfo de Sanlucar por la Costa del Sur, hasta el río del enpa ynclusible nor deste sudueste de mar a mar que entre el Golfo y provincia de las Higueras y puerto y cabo de Honduras, porque conviene a servicio de vuestra Magestade a la sustentación destas dos gobernaciones que se junten porque una favorezca a la otra y se pueble y pacifique la tierra y porque esta governación no tiene puerto ninguno a la mar del norte por donde se provea y bastezca de las cosa necesarias. (Argüello, 1994:63).
\end{abstract}

El 15 de septiembre de 1821, América Central se declaraba independiente de España, después de 10 años de conflictos armados. Al año siguiente, se unía al imperio mexicano de Iturbide para crear un vasto conjunto político que se extendía desde California hasta Panamá (ex-

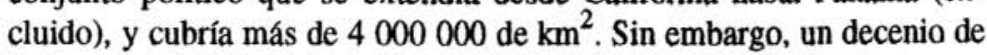
guerra contra un enemigo común no había logrado forjar una nación centroamericana ni dar forma a un espacio coherente en el istmo. Esa derrota se explica en parte porque el patriotismo americano reivindicado por los criollos, se aplicaba sobre todo a nivel local y regional. Además, los lazos económicos entre las diversas provincias habían quedado débiles. Muy pronto, las fuerzas centrífugas pudieron más que las tentativas de unión reivindicadas por los primeros revolucionarios. Entonces las fracturas siguieron a menudo los límites administrativos más o menos teóricos impuestos por la colonia, cada provincia doblegándose sobre sí misma y sobre su ciudad principal.

La primera ruptura se dio en 1823 , cuando América Central se apartó del imperio mexicano, a la caída de Iturbide. La antigua capitanía de Guatemala volvió a encontrar su autonomía, perdiendo a Chiapas (recuperado por México). Una federación centroamericana estaba entonces constituida: las Provincias Unidas de América Central, agrupando cinco estados: Guatemala, El Salvador, Honduras, Nicaragua y Costa Rica.

La Constitución federal de esa nueva entidad política daba gran autonomía a los diferentes Estados-miembros, a pesar de la presencia de un presidente de la federación instalado en la ciudad de Guatemala. El primer presidente titular, elegido en 1825 , fue el general salvadoreño Manuel José Arce. Sin embargo, muy pronto fue combatido por sus 
antiguos amigos liberales, por lo que estalla una guerra civil entre Guatemala - sede del poder - y dos provincias rebeldes - Honduras y El Salvador- en 1826. Después de varios años de lucha, el hondureño Francisco Morazán estaría al frente de la federación y encarnaría hasta su muerte en 1842, el ideal de la unión centroamericana. Su carrera política demuestra hasta qué punto, en esa época, las fronteras eran poco herméticas: elegido presidente de Honduras en 1827, fue nombrado presidente de El Salvador en 1839, y luego de Costa Rica en 1842. En 1840, su derrota militar frente al dictador guatemalteco Rafael Carrera, daría fin a una federación moribunda, de la cual ya se habían separado Costa Rica, Honduras y Nicaragua.

En el curso de ese periodo, el mito persistente de una gran patria centroamericana a menudo fue confrontado con otro ideal, el de las "patrias chicas", alimentado por los discursos nacionalistas de los liberales en el poder a fines del siglo XIX, en casi todos los países del istmo. En 1883, de manera altamente simbólica, El Salvador decidió acuñar su propia moneda, bajo la instigación del presidente Zaldívar, a pesar de que, hasta esa fecha, varias monedas extranjeras tenían curso sobre su territorio. ${ }^{8}$

En la segunda parte del siglo XIX, cuando la idea de una nación centroamericana se hacía más y más imprecisa, todos los dirigentes centroamericanos multiplicaron los gestos y los signos nacionalistas para fundamentar la legitimidad de las repúblicas nacidas de la descomposición del imperio español. Desde esa perspectiva, es interesante constatar que, en la mayoría de los casos, el verdadero nacimiento del país se remonta en el momento en que los diferentes Estados logran desprenderse (en el plan simbólico) del resto de la América Central. La cartografía juega entonces el papel principal en la definición de los nuevos espacios nacionales, que permite representar, de manera supuestamente objetiva, la idea de patria.

En 1995, el Instituto Nicaragüense de Estudios Territoriales (Ineter), publicó un pequeño libro intitulado Maximiliano von Sonnenstern y el primer mapa oficial de la república de Nicaragua, cuyo subtítulo era: Contribución a la historia de la cartografía nacional. (Juárez, 1995). En esa obra, el autor señala que el mapa realizado en 1858 por Maximiliano Von Sonnenstern era el primer mapa nacional de Nicaragua, después de

\footnotetext{
8 Sin embargo fue en 1892, es decir, diez años más tarde, que ese decreto presidencial se aplicó (Acuña Ortega, 1997). Todavía hoy en día, por el hecho de la presencia estadounidense en la zona del canal, la moneda oficial de Panamá es en gran parte ficticia: el balboa es, en efecto, la versión local del dólar de los Estados Unidos. Sí se aceptan pequeñas monedas de débil valor (un cuarto de balboa, por ejemplo), pero únicamente los billetes verdes emitidos por Wáshington, circulan en el interior de la pequeña república panameña, cuyo sueño es de integrarse lo más posible al Tratado de Libre Comercio Norteamericano.
} 
varios siglos de una cartografía española puramente administrativa que ponía en la misma bolsa todas las provincias de la Capitanía General de Guatemala. Si bien es cierto que este mapa está particularmente bien detallado - lo que muestra el fruto de un trabajo largo de archivos y de terreno-, es sobre otro punto que se distingue de anteriores ilustraciones del territorio nicaragüense: hasta finales de los años 1850 , se encontraban mapas del conjunto de América Central que cubrían toda la extensión del istmo, pero es con Maximiliano Von Sonnenstern que, por primera vez, Nicaragua está representado solo, aislado, cortado de sus vecinos. Mientras que en la parte central, las indicaciones tipográficas abundan y hacen confusa la lectura del documento, las fronteras políticas del Estado sirven aquí de límites para la representación cartográfica (figura 3). ${ }^{9}$ Las montañas desaparecen, los ríos dejan de fluir, las carreteras están cortadas tan pronto como salimos del territorio nicaragüense. En el norte, Honduras no es más que un vasto desierto blanco; en el sur, los márgenes costarricenses están todavía bien representados, porque cubren una zona que pertenecía históricamente a la provincia de Nicaragua.

No es una casualidad que el Ineter haya decidido volver a editar el mapa de Sonnenstern y consagrarle un estudio presentado en la contraportada como "una notable contribución a la geografía, la historia y la cultura patria“. Una vez más, la geografía y la cartografía no son más que útiles al servicio de una visión geopolítica claramente anunciada. En efecto, siempre, según el texto de presentación del libro de Orient Bolívar Juárez, los mapas reproducidos son particularmente importantes "ya que en ellos se puede constatar la incuestionable pertenencia a Nicaragua, de las islas de San Andrés y Providencia, así como la vasta comprensión territorial que tenía Nicaragua en tiempos de la colonia". De hecho, la fijación de las fronteras queda como tema fundamental en la retórica nacionalista de los pueblos centroamericanos. Mar adentro de Mosquitia, granitos de arena perdidos en el mar Caribe (las pequeñas islas Providencia y San Andrés), pertenecían a Colombia, pero siempre reivindicadas por Nicaragua, so pretexto que se sitúan en la prolongación de la costa atlántica del país. ${ }^{10}$

De la misma manera, el recuerdo de la extensión histórica de Nicaragua permite cuestionar de nuevo las fronteras que le han sido impuestas en el

9 Por razones técnicas, hemos decidido reproducir la versión simplificada de ese mapa, publicado en 1847 en la Jeografía de Nicaragua para el uso de las escuelas primarias de la república, del mismo Maximiliano Von Sonnenstern.

${ }^{10}$ Lo que está en juego es, en efecto, la distancia, porque las islas en cuestión, así como algunos cayos aislados, se sitúan a $200 \mathrm{~km}$ de las costas nicaragüenses y están a más de 600 $\mathrm{km}$ de Colombia. Ahora bien, la plataforma continental podría contener importantes yacimientos de hidrocarburos. 


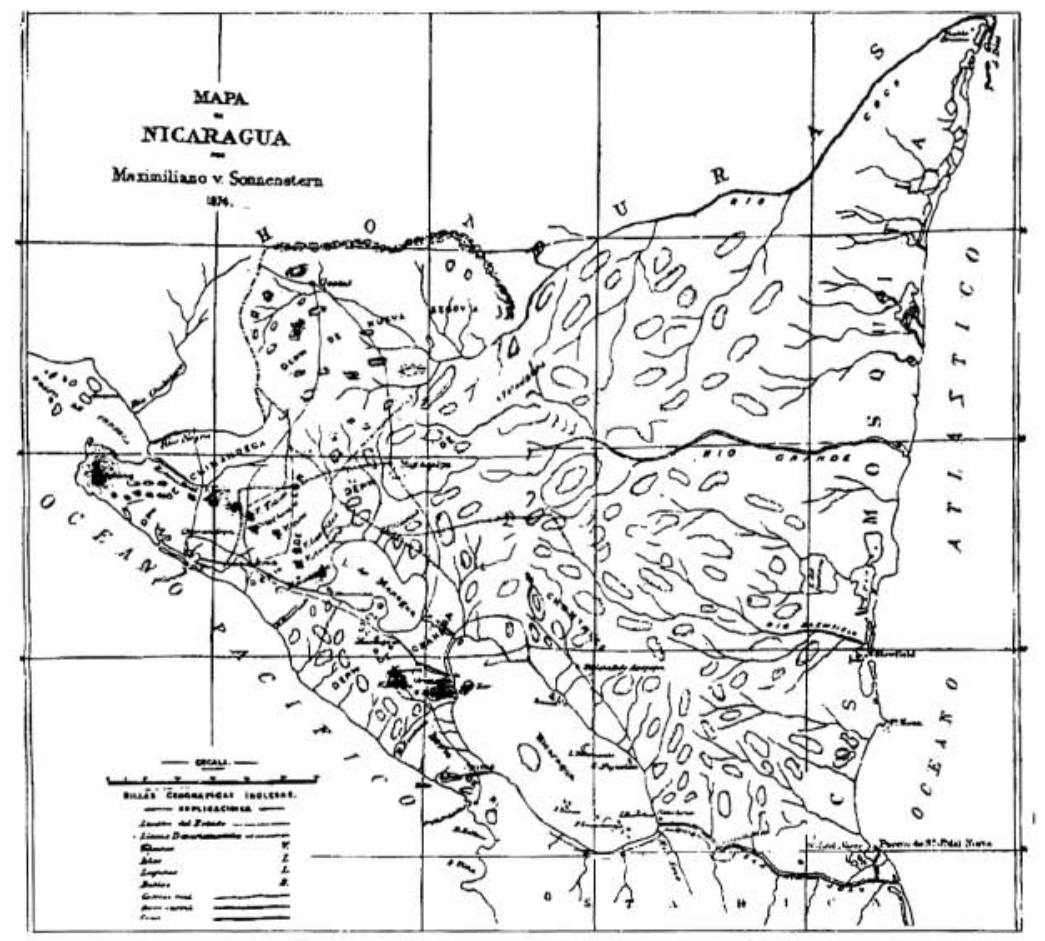

Figura 3. Mapa de Nicaragua. Maximiliano V. Sonnenstern, 1874. 
curso del siglo XIX. En su Jeografia de Nicaragua para el uso de las escuelas primarias de la república (1875), Maximiliano Von Sonnenstern hacía que el alumno dijera, en un juego clásico de preguntas y respuestas con su maestro: "esto es lo establecido en el Tratado de límites de 1858, cuya validez está actualmente en cuestión".

Esa búsqueda de la identidad nacional pasa, pues, por el reconocimiento internacional del estatuto de las fronteras, del cual todos los Estados centroamericanos tratan de remontar lo más lejos posible en el tiempo la validez jurídica. ${ }^{11}$ Es revelador constatar que en su Geografía dinámica de Nicaragua, publicada en 1995, Jaime Incer emplea casi palabra por palabra las mismas oraciones que Sonnenstern, cuando define el trazado de la frontera entre su país y Nicaragua:

La frontera sur, que nos separa de la República de Costa Rica, se inicia en la bahía de Salinas, en el océano Pacífico, de donde sale en línea directa hasta encontrar al río Sapoá, a unas dos millas antes de su desembocadura en el lago de Nicaragua. Desde este punto corre paralela al lago, manteniéndose siempre a unas dos millas de la costa lacustre y de la ribera sur del río San Juan, hasta un punto situado a unos $5 \mathrm{~km}$ aguas abajo de el Castillo, punto donde la ribera del río pasa a ser frontera común y así hasta la desembocadura en San Juan del Norte. (Incer, 1995:I-12). ${ }^{12}$

La antigua medida inglesa aún se menciona, ya que fue con ese sistema que los límites territoriales fueron fijados entre las dos partes. En su obra, Jaime Incer insiste sobre el hecho de que Nicaragua ejerce una soberanía completa sobre el curso del río San Juan, aunque acuerdos bilaterales permiten a los costarricenses utilizarlo para el transporte de mercancías, a partir del punto donde la frontera entre los dos países se junta con la ribera derecha del río.

\footnotetext{
${ }^{11}$ La novela de Miguel Ángel Asturias, El papa verde, pone en escena a un pequeño maestro de escuela, Moisés Guasper, que encuentra en los archivos nacionales de su país una vieja cédula real que trata de las divisiones administrativas de la antigua capitanía. Ese documento permite a una compañía bananera estadounidense reivindicar territorios situados del otro lado de la frontera.

${ }^{12}$ En su Jeografia de Nicaragua para el uso de las escuelas primarias de la república, Maximiliano Von Sonnesnstern escribió, 120 años antes: la línea divisoria entre Nicaragua y Costa Rica

comienza en media bahía de Salinas, tira una línea astronómica al rio Sapoá, dos millas inglesas distante del Gran Lago de Nicaragua. De allí a la misma distancia del lago i del rio de San Juan hasta el fuerte del Castillo Viejo en donde se forma un círculo de tres millas inglesas; de este punto sigue la línea de la marjen derecha del río San Juan hasta la punta de Castilla en frente de San Juan del Norte.
} 
El carácter quisquilloso, puntilloso y a menudo litigioso de las fronteras centroamericanas, se explica por la recurrente necesidad que tienen los Estados de justificar el carácter intocable — podríamos decir sagrado- de esos límites políticos, que quedan mal anclados en el medio físico y cultural de la región. De hecho, todo el problema reside en la adecuación entre la línea (la frontera) y el espacio (el territorio): si todo el mundo concuerda en considerar que existen en América Central espacios distintos, son precisamente esas líneas de separación entre esos diferentes espacios las que son difíciles de delimitar y precisar. Es por eso que hay que evitar jugar con las palabras. Es cierto, la parte más grande del trazado de las fronteras ha sido fijada después de la época colonial, pero los territorios existían antes de la delimitación definitiva. ${ }^{13}$ Para resolver sus discrepancias, los Estados centroamericanos se valieron de numerosos arbitrajes internacionales, cuyas opiniones se referían sistemáticamente a los mapas oficiales con el fin de mostrar el carácter indiscutible. El mapa político de Honduras señala, así, que la frontera con Guatemala fue fijada por el Laudo de Wáshington del 23 de enero de 1933. El límite con Nicaragua fue discutido de manera más larga y áspera, como lo indica la leyenda que trata del documento oficial: "actas de la comisión mixta de límites de 1900-1901, laudo del rey de España del 23 de diciembre de 1906, ratificado por el fallo de la corte internacional de justicia de La Haya el 18 de noviembre de 1960 ".

A pesar de todas esas precauciones, al principio de los años ochenta, los sandinistas no se detuvieron a cambiar un cierto número de límitesfronteras en zonas consideradas como estratégicas por el hecho de la presencia sobre el suelo hondureño de numerosos grupos contrarrevolucionarios sostenidos por los Estados Unidos.

\section{¿FRONTERAS VIVAS O FRONTERAS MUERTAS?}

Las fronteras centroamericanas constantemente han sido espacios conflictivos, aunque las tensiones internas y externas han disminuido notablemente desde el principio de los años noventa. En 1991, Guatemala y Belice, decididos a dar término a sus querellas fronterizas, establecieron relaciones diplomáticas por vez primera. Anterior a esa fecha, las autoridades guatemaltecas se habían rehusado a reconocer a la antigua colonia británica (posteriormente, Estado independiente de Belice).

\footnotetext{
13 "Por lo contrario a una opinión difundida, los trazos no son exactamente los que preceden del periodo colonial; en la mayoría de los casos son posteriores a fines del siglo XVIII y los ogígenes han sido diversificados" (Foucher, 1991:135).
} 
El ejército organizaba maniobras en la selva de Petén, mientras que el Estado suscitaba un gran movimiento de colonización agrícola destinado no solamente a reducir la tensión territorial sobre las tierras altas centrales, sino también con el fin de poblar espacios marginales, a menudo insalubres, considerados estratégicos por su situación en la orilla de los territorios reivindicados por los militares.

Hoy en día, Belice ya no es oficialmente considerada por los guatemaltecos como una provincia rebelde, pero la cartografía conserva la huella de esas viejas reivindicaciones nacionalistas. Sobre numerosos mapas que están todavía en circulación, particularmente los publicados por el Instituto Guatemalteco de Turismo, Belice está representado como un simple departamento, y Belmopan, su capital, aparece como una "cabecera departamental", en el mismo título que Flores para Petén o Cobán para la Alta Verapaz.

La segunda gran zona potencial de conflictos se encuentra en la frontera entre Honduras y El Salvador, aunque el reglamento de las discrepancias internas y el regreso a la paz civil han favorecido que la tensión entre los dos países disminuya. Después de un decenio perdido (los años setenta), un acuerdo de paz fue firmado en 1980, pero fue hasta 1992 cuando se tomó la decisión que arreglara los litigios fronterizos que envenenaban las relaciones de las dos repúblicas desde la independencia. Los puntos más discutidos han sido resueltos por la Corte Internacional de La Haya, en gran parte en beneficio de El Salvador. ${ }^{14}$ Sin embargo, esos avances diplomáticos no han impedido a los militares multiplicar las provocaciones en ambos lados de la frontera, mientras que numerosos salvadoreños continúan estableciéndose ilegalmente en el país vecino. Esa inmigración clandestina alimenta el discurso xenófobo de una parte de la clase política hondureña y pone en riesgo los acuerdos de paz firmados por los dirigentes de los dos Estados. De hecho, desde la mitad de la década de 1990, bandas armadas y grupos sin control han pretendido remplazar a las tropas regulares para asegurar la defensa de la línea fronteriza con El Salvador, acusado de miradas expansionistas.

Sobre la ladera este de Honduras, en cambio, la presión militar disminuyó desde que los sandinistas en el poder en Nicaragua fueron derrotados durante la elección presidencial de 1990. Los Estados Unidos dejaron de apoyar a los oponentes instalados del lado hondureño de la frontera, y la situación en torno a los ejes principales de las carreteras que atraviesan

\footnotetext{
${ }^{14}$ Particularmente tres zonas sensibles: los bolsones de Sazalapa-La Virtud, Tepanguisir y Cayanguaca, donde el trazado de la frontera ha sido rectificado en detrimento de los departamentos hondureños de Lempira y Ocotepeque.
} 
la región - como la carretera panamericana, verdadera espina dorsal de los flujos intrarregionales-, empeoró. Los campamentos de la "contra" fueron desmantelados, las bases de apoyo estadounidenses fueron abandonadas en su mayoría, y los límites desplazados por los sandinistas, fueron puestos de nuevo en su lugar. Los nicaragüenses reconocen que ya no hay más litigio fronterizo entre ellos y sus vecinos, aunque con gusto hacen notar que en la época colonial los límites de su provincia subían hacia el norte hasta el río Aguan (río Patuca), y que buena parte del noreste hondureño les pertenecía (por lo menos formalmente).

Esa situación permanente de crisis se explica porque, desde la mitad del siglo XIX, las querellas de frontera entre países centroamericanos han sido la causa de varias guerras que han dejado profundas cicatrices no solamente sobre los mapas, sino también sobre el terreno y en los espíritus. Esos conflictos fueron exacerbados con la intervención de numerosas compañías bananeras de origen estadounidense, que querían apropiarse de las mejores tierras con el fin de desarrollar su sistema de plantación. De esta forma, a finales de los años veinte, la Cuyamel Fruit Company fomentó el patriotismo de los hondureños y trató de que se enfrentaran a sus vecinos guatemaltecos. El objetivo de la operación era desalojar a la United Fruit Company de los terrenos que había adquirido a lo largo del río Matagua, empujando la frontera entre los dos países hacia el oeste. ${ }^{15}$ Los Estados Unidos se interpusieron entonces entre los beligerantes, e impusieron su arbitraje a favor de Guatemala (es decir, de la United Fruit) y en contra de Honduras (es decir, de la Cuyamel). La frontera es, desde entonces, la que fue fijada por el famoso Laudo de Wáshington del $23 \mathrm{de}$ enero de 1933, tal y como está indicado en la cartografía oficial de Honduras. En cuanto a las dos compañías bananeras enemigas, fueron obligadas a fusionarse después de la gran crisis económica de 1929, lo que hace aún más absurdo el conflicto entre Honduras y Guatemala en esa época.

La génesis de los Estados centroamericanos, y la persistencia de las tensiones internas (guerrillas, guerras civiles) y externas (reivindicaciones territoriales, patriotismo exacerbado), permiten entender mejor porqué los espacios fronterizos se han mantenido por mucho tiempo como zonas marginadas, gozando muy poco del beneficio de la situación conferida por su estatuto jurídico particular, contrario a lo que sucede en otras regiones del mundo.

${ }^{15}$ Ese episodio poco glorioso, es relatado de manera romanesca en la obra de Miguel Ángel Asturias, El papa verde. 
Desatendidas y mal controladas por las autoridades gubernamentales, pero al mismo tiempo consideradas estratégicas por los militares, estas zonas acumulan todas las desventajas. Si se mira un mapa de América Central (figura1), es notoria la escasez de polos urbanos situados cerca de una frontera del Estado. En la mayoría de los casos, las aglomeraciones situadas en contacto entre dos países, son de importancia mediocre y sus actividades se limitan a operaciones rudimentarias (transporte, aduanas, comercio).

En ese contexto, podríamos creer que la carretera panamericana juega un papel decisivo, favoreciendo los intercambios entre los países del istmo y permitiendo el desenclave de regiones fronterizas. De hecho, constatamos que el espacio fronterizo "oficial" o formal, limitado por una línea sencilla sobre la mayoría de su trazado, se dilata en ambos lados de los límites del Estado, cuando puede seguir los ejes principales de comunicación. ${ }^{16}$

Algunas ciudades localizadas a cierta distancia de la frontera, pueden pertenecer así a su zona de influencia o mantener relaciones privilegiadas con ella. Es el caso de Rivas, en Nicaragua, situada a $35 \mathrm{~km}$ de la frontera costarricense, pero también de David, en Panamá (a 53 km de Costa Rica), o de Choluteca, en Honduras, que se encuentra casi a mitad del camino entre El Salvador (a $85 \mathrm{~km}$ ) y Nicaragua $(\mathrm{a} 60 \mathrm{~km})$. Por lo tanto, el concepto de ciudad-frontera en América Central debe reconsiderarse: no es necesariamente la distancia en comparación con el cruce que cuenta, sino el nivel de integración de las actividades urbanas con las estructuras de la economía fronteriza.

Sin embargo, a pesar de su importancia para cada Estado, la influencia de la carretera panamericana es aún bastante débil, debido a los años de guerra civil que bloquearon por mucho tiempo el desarrollo de los transportes terrestres entre los diferentes países de la región. El caso de la ciudad de Choluteca, es en ese aspecto, particularmente revelador de los problemas suscitados por el carácter ambiguo de las fronteras centroamericanas: vías de tránsito obligadas para todas las mercancías producidas en el lugar o importadas de otro país; son también espacios frágiles, directamente perturbados por todas las turbulencias que afectaron a los países de la región en el curso de los últimos 20 años. Por eso Choluteca, ciudad

${ }^{16}$ Ese espacio es caracterizado por actividades económicas específicas (transportes, servicios bancarios), y también por prácticas sociales y culturales particulares, relacionadas con el crecimiento de los intercambios comerciales y con las migraciones alternas. El espacio fronterizo no oficial también puede extenderse, y más, ya que abarca todas las actividades de contrabando relacionadas, entre otras, al tráfico de drogas, pero se identifica y se delimita difícilmente, en particular en las regiones de la sierra y de la selva. 
hondureña situada de manera ideal sobre la carretera panamericana entre El Salvador y Nicaragua, aún no ha obtenido todos los beneficios de una situación teóricamente privilegiada.

$\mathrm{Al}$ principio de los años setenta, la guerra del futbol con Salvador ocasionó el derrumbamiento de las relaciones con la república vecina, cuando la apertura del Mercomún Centroamericano, durante el decenio anterior, había permitido intensificar los intercambios entre las dos regiones situadas en ambas partes de la frontera. En el curso de ese periodo, la expulsión de numerosos salvadoreños, y el retroceso de las actividades industriales o comerciales, acentuaron el aislamiento de Choluteca, cabecera departamental orientada hacia su terruño agrícola desde hace mucho tiempo. El principio de una reconciliación con El Salvador, en 1980, no permitió volver a dinamizar la economía local. En efecto, la toma de Nicaragua por los sandinistas (1979) provocó rápidamente la clausura de la frontera oriental. La guerra civil que continuaría y la intervención de los Estados Unidos en el conflicto, tuvieron consecuencias inmediatas en esa zona sensible: el paro de las exportaciones hondureñas hacia Nicaragua y la interrupción de casi todo el tráfico internacional sobre la carretera panamericana.

Desde los años noventa, el apaciguamiento de las tensiones internacionales permitió a Choluteca recobrar su función de tránsito. Aunque incompletas, las encuestas de la Secretaría de Obras Públicas y Transportes (Secopt) muestran que el tráfico se reanudó entre la capital del departamento y la zona fronteriza. En 1995, el tráfico medio a la salida de Choluteca hacia Somoto (Nicaragua) vía San Marcos de Colón, era de 677 vehículos al día (casi $80 \%$ del tráfico dedicado al transporte de mercancías). Recientemente pavimentada y bien mantenida, la carretera del sur (CA-3) hacia Somotillo (Nicaragua) vía Guasaule, registraba un promedio diario de 1888 vehículos, de los cuales solamente 161 eran carros particulares y 70 autobuses, el resto lo constituían camiones y pick-ups (vehículos destinados esencialmente al transporte local de mercancías).

A la orilla de la carretera, a la salida de la ciudad, la presencia de numerosas gasolinerías y talleres mecánicos para la compostura de carros, comprueba que el flujo volvió a ser constante y regular. Realmente Choluteca no estaba integrada a la economía regional transfronteriza, ya que sus grandes actividades agroexportadoras (camarones, melones) se enfocaban hacia mercados más lejanos, principalmente a los Estados Unidos (Hardy, 1997). Sin embargo, los años de guerra favorecieron la creación de redes comerciales no oficiales entre los tres países ubicados en la región. Los costos de producciones débiles (relacionadas con el bajo 
salario de los obreros agrícolas, con las disponibilidades de tierras cultivables y con la estabilidad relativa del país) permitieron a numerosos comerciantes exportar hacia El Salvador y Nicaragua productos alimenticios para los lugareños, a pesar de la oposición de las autoridades locales y nacionales.

Desde 1992, la ley de modernización agrícola adoptada por el estado hondureño, autoriza de nuevo la venta al extranjero de esas mercancías que, por mucho tiempo, fueron consideradas como estratégicas, porque el equilibrio alimenticio de la nación dependía de ello. Podemos entonces suponer que el conjunto del departamento pensado entre las dos fronteras, ${ }^{17}$ debería beneficiarse de esas nuevas disposiciones: la carretera panamericana permitiría, por lo tanto, facilitar la integración de los productores locales a la economía regional, descartando el carácter de enclave agroexportador de Choluteca.

La noción de enclave es, de hecho, una constante en el mundo centroamericano, encuadrada y fijada por sus fronteras internas y externas. Por ello que dudamos en considerarla una frontera viva, que permite el manejo de los bienes y de las personas, o bien, una frontera muerta, prohibida de acceso, verdadero callejón sin salida donde se pierde la energía de las nociones del istmo. La antigua zona del canal de Panamá es, desde esa perspectiva una verdadera caricatura. Impuesta en 1903 por los Estados Unidos a la joven república panameña, a cambio de una módica pensión alimenticia sustraída de los beneficios del tráfico transoceánico, esa banda de $1500 \mathrm{~km}^{2}$ permaneció por mucho tiempo, como una herida no cicatrizada en el orgullo nacional panameño. Hubo que esperar hasta 1977 y la firma de los Acuerdos Torrijos-Carter, para que el asunto de la entrega de los territorios bajo el control estadounidense fuera parcialmente resuelto: en el año 2000, la totalidad de las zonas ocupadas por los Marines será restituida al gobierno de Panamá, que estará completamente a cargo de la gestión de los asuntos del canal. Pero por encima de los símbolos, se trata, para el Estado panameño, de organizar la reconquista (o mejor dicho, la conquista) de esa frontera interior que constituye la zona del canal, y de facilitar la integración al territorio nacional de un antiguo enclave que, hasta entonces, funcionaba según reglas y leyes de origen extrajero.

Para calificar ese gran logro, los discursos oficiales privilegian ciertos términos (reintegración, recuperación, reincorporación) que no reflejan por completo la verdad histórica, ya que la zona del canal, concebida por

\footnotetext{
17 Tomando en cuenta la presencia en el oeste del pequeño departamento de Valle sobre la frontera salvadoreña.
} 
y para los estadourridenses, realmente nunca perteneció a la república panameña. Desde el origen, la antigua provincia colombiana fue cortada en dos partes: sobre el papel primeramente, luego sobre el terreno, para permitir a los políticos de Wáshington controlar un espacio considerado vital para los intereses regionales y mundiales. Esa frontera interior marco de manera duradera no solamente a la-nación panameña, que construyó gran parte de su identidad cultural y política alrededor de ese absceso de fijación, sino también la historia y geografía de Panamá. De esta manera el desarrollo urbano de la capital se llevó a cabo en un contexto espacial particular, ya que una parte de la ciudad pertenecía a la zona estadounidense (barrios de Ancón y de Balboa), lo que desvió hacia el oeste y hacia el norte la expansión de nuevos barrios destinados a las poblaciones panameñas, fueran ricas o pobres.

Una de las posturas actuales de la reintegración de la zona del canal consiste, pues, en revitalizar espacios hasta entonces monopolizados y esterilizados por las bases estadounidenses, pero también en favorecer la apropiación por los panameños de los barrios abandonados por sus antiguos ocupantes.

En marzo de 1993, el gobierno decidió la creación de un organismo encargado de la devolución de las áreas y de los bienes de la antigua zona del canal: la ARI (Autoridad de la Región Interocéanica). A pesar de algunas fallas, ligadas a la naturaleza jurídica y política de esa institución, ${ }^{18}$ la ARI juega, de ahora en adelante, un papel central en los procesos de recomposición de los espacios que serán devueltos por los estadounidenses (Blanchemanche, 1997). El fin de ese enclave marca, pues, el principio de una nueva era no solamente para Panamá, sino también para América Central en su conjunto. De hecho, la retirada de los Estados Unidos permite a los panameños considerar nuevas relaciones con sus vecinos inmediatos. Bajo esa perspectiva, la presentación en $1994^{19}$ de un proyecto de la "Ciudad del Saber", destinada a remplazar las instalaciones de la base aérea de Albrook (definitivamente evacuada en 1997), marcaba la voluntad del gobierno panameño de romper con su aislamiento, pero también de sustituir la imagen negativa de los soldados estadounidenses por la de estudiantes venidos de todos los países del istmo.

\footnotetext{
${ }^{18}$ La ARI está situada bajo el control directo del Estado y administra un presupuesto importante ( 31000000 de dólares en 1995). Es pues, un instrumento estratégico, pero cuya gestión parece a veces carecer de transparencia.

${ }^{9}$ Durante la Cumbre de las Américas organizada en Miami, Florida, EUA.
} 


\section{CONCLUSIÓN: ¿HACIA LA INTEGRACIÓN POLÍTICA DE LOS PAÍSES DEL ISTMO?}

La historia de América Central, como la de la América española en su conjunto, está marcada por el sueño de la unidad perdida. En 1826, Simón Bolívar organizaba en Panamá el Primer Congreso de los Estados Americanos. Tenía la intención de crear una vasta federación latinoamericana capaz de enfrentar a las potencias europeas, y también los apetitos nacientes de los Estados Unidos. Ese sueño de una "Nación de Repúblicas", por retomar su expresión, fracasó ante la intransigencia de las oligarquías locales, cuidadosas en defender ante todo sus intereses particulares. La derrota de las federaciones regionales tanto en los Andes, con la gran Colombia (1819-1830), como en el istmo, con las Provincias Unidas de América Central, ilustra las dificultades encontradas por América Latina para liberarse de sus fronteras internas. Sin embargo, desde el principio del siglo XX, el Partido Unionista Centroamericano, cuyo principal inspirador era el nicaragüense Salvador Mendieta, empezó a reclamar la creación de una nueva confederación centroamericana que, sin suprimir los Estados existentes, permitiría abolir fronteras consideradas absurdas y nefastas.

En 1921 nacía una nueva entidad política: la Federación de Centroamérica, que agrupaba a Guatemala, Honduras, Costa Rica y El Salvador. Nicaragua, ocupada por los marines estadounidenses era, de manera provisional, descartada del proyecto, aunque se le daba la posibilidad de adherirse posteriormente a la federación, con la condición de aceptar todos los términos del tratado de la unión. Cada Estado miembro conservaba su autonomía y su independencia para administrar sus asuntos internos, pero estaba previsto crear un gobierno federal (teniendo como capital a Tegucigalpa), elegir una asamblea constituyente y unir a todos los ejércitos nacionales bajo una misma bandera. Desafortunadamente, los Estados Unidos no hicieron nada para apoyar ese vasto programa; al contrario, continuaron ocupando Nicaragua y cerraron los ojos sobre la invasión de una parte del territorio costarricense por el ejército panameño (marzo de 1921). El gobierno de San José decidió, pues, no ratificar el tratado y regresar a su tradicional aislamiento. Todavía hoy en día, los costarricenses consideran que no pertenecen a América Central: según ellos, su sistema político y su nivel de vida los distinguen de sus vecinos, considerados demasiado violentos y muy poco dotados para la democracia.

En 1923, un nuevo tratado de paz y de amistad entre los diferentes países fue firmado. Era el primer paso hacia la constitución de un organismo encargado de promover los intercambios comerciales y culturales a 
nivel regional: la Organización de Estados de América Central. Fundada en 1951 en San Salvador, la ODECA agrupa a Guatemala, Honduras, El Salvador y Costa Rica. Desde 1962, la organización descansa sobre dos consejos (ejecutivo y legislativo) y se apoya sobre una Corte de Justicia Internacional, un Centro Cultural y un Consejo de Defensa Centroamericano. El grupo está dirigido por la Conferencia de los Jefes de Estado y la de los Secretarios de Relaciones Extranjeras, que se reúnen regularmente. Desde el documento firmado en 1977 (Tratados Torrijos-Carter), que tiene que ver con la soberanía del canal interoceánico, Panamá se acercó a la ODECA, que no le había cerrado las puertas completamente. Durante el periodo 1991-1992, el Estado panameño, traumatizado por la dictadura del general Noriega y por la intervención estadounidense en diciembre de 1989, suprimió a su ejército (remplazado por una fuerza policiaca) y aceptó pertenecer a la comunidad centroamericana. Esa adhesión permitió considerar una reactivación de un proyecto de unión que había conocido una derrota importante con el rechazo, en 1976, de una comunidad económica y social entre los cinco países miembros de la ODECA.

Dicho proceso de unificación se hizo posible debido al fin de las tensiones políticas internas de cada país, y también al arreglo progresivo de los puntos de litigio fronterizos. Pero antes de cualquier unión política, que parece todavía limitada a algunos aspectos simbólicos (un parlamento centroamericano sin poder real o placas de matriculación estampadas como Centroamérica), la integración regional pasa, sin lugar a dudas, por la reactivación del Mercomún Centroamericano (MCCA) que, a pesar de sus límites, ${ }^{20}$ tuvo un fuerte impacto en el desarrollo de América Central en el curso del decenio 1960-1970.

En 1990, el Mercomún Centroamericano (con efectos prácticos muy reducidos) se limitaba de hecho a tres países: Guatemala, El Salvador y Costa Rica. En 1987, sin embargo, el acuerdo de Esquipulas II insistía sobre la necesidad de una mejor cooperación económica entre los diferentes países de la región para devolver la calma y la prosperidad en América Central. Desde el principio de los años noventa el regreso de la paz en varios países marcados con años de guerra civil (Guatemala, Nicaragua, El Salvador), permitió reflexionar sobre nuevos proyectos de integración regional, fundados esta vez sobre la economía del mercado, la libre empresa y la internacionalización de los intercambios. Se trata, de hecho,

${ }^{20} \mathrm{El} \mathrm{MCCA}$, en efecto, favoreció industrias no competitivas sobre el plan internacional, acentuó el peso del contrabando en los intercambios y agravó las disparidades regionales entre los países más industrializados (Guatemala y El Salvador) y los países avanzados (Honduras y Nicaragua). 
de utililzar las ventajas comparativas de los países del istmo para desarrollar las exportaciones de los productos agrícolas o industriales.

En octubre de 1993, los diferentes Estados centroamericanos firmaron en Guatemala un Protocolo al tratado general de integración económica centroamericana que fijó las bases de la futura cooperación regional en varios dominios fundamentales: la unión aduanera, la libre circulación de las personas y de las mercancías, y la armonización de las relaciones comerciales con el exterior.

Sin embargo, a pesar de ese adelanto, no se puede hablar de una verdadera integración regional, porque cada Estado conserva el derecho de firmar los acuerdos bilaterales con terceros países, ${ }^{21}$ y nada está previsto en el protocolo para animar la unión política de los Estados miembros, incluso bajo la forma tan vil de una confederación (Fernandez Arias y Abarca Amador, 1995:9-37).

Así, ni la aceleración del proceso de paz, ni el fuerte impacto de la globalización de los intercambios sobre las economías locales, parecen amenazar la permanencia y la continuidad de las fronteras del istmo. Pero si están siempre presentes, su papel puede evolucionar: la apertura económica querida por todos los jefes de Estado de la región permitirá quizás a esos espacios marginados por mucho tiempo, ser los nuevos ejes del desarrollo centroamericano.

${ }^{21}$ Por lo tanto, un tratado de libre comercio entre México y Panamá debería ser concluido antes de abril de 1998, en coordinación con el Pacto Regional México-América Central, cuyo fin es crear una zona de libre intercambio desde el río Bravo hasta la frontera colombiana. 


\section{BIBLIOGRAFÍA}

ACUÑA Ortega, Víctor Hugo. 1997. "Nación y clase obrera en centroamérica en la época liberal (1870-1930)", en Musset, Alain y Thomas Calvo (eds.), Des Indes occidentales à l'Amérique latine, CEMCA-ENS-IHEAL, tomo 2, París.

ARGÜELLO Argüello, Alfonso. 1994. Historia de León Viejo, León, Nicaragua, Editorial Hospicio.

BERTRAND, Michel. 1987. Terre et société coloniale. Les communautes Maya-Quiché de la région de Rabinal du XVIe au XIXe siècle. México, CEMCA.

BLANCHEMANCHE, Alain. 1996. La rétrocession de la Zone du Canal de Panamá: l'enclave, les contraintes et la réintégration. Memoria de la DEA, Nanterre, Universida de París X.

COLLECTIVO. 1993. Historia general de Centroamérica, 6 vols., Madrid, Sociedad Estatal Quinto Centenario-FLACso.

FERNÁNDEZ Arias, Mario E. y Ethel Abarca Amador. 1995. "El Protocolo al tratado general de integración económica centroamericana: ¿Base de desarrollo o tumba del proceso integracionista?", Anuario de Estudios Centroamericanos, Universidad de Costa Rica, vol.21 (1-2), p. 9-37.

FOUCHER, Michel. 1991. Fronts et frontières, un tour du monde géopolitique, París, Fayard.

HARDY, Sébastien. 1997. Choluteca, une ville intermédiaire au Honduras. Memoria de la maestría en geografía, Nanterre, Université de Paris $\mathrm{X}$.

INCER, Jaime. 1995. Geografía dinámica de Nicaragua, Managua, Nicaragua, Ed. Hispamer.

JUÁREZ, Orient Bolívar. 1995. Maximiliano Von Sonnenstern y el primer mapa oficial de la República de Nicaragua, Managua, Nicaragua, INETER.

MUSSET, Alain. 1994. L'Amérique centrale et les Antilles, une approche géographique, París, Masson.

SELIGSON, Mitchell A. 1993. "Actitudes de la población centroamericana frente a la integración política y económica" Anuario de estudios centroamericanos, Universidad de Costa Rica, vol. 19 (2), p. 7-24.

VELÁZQUEZ Pereira, José Luis. 1992. La formación del Estado en Nicaragua, 1860-1930, Managua, Nicaragua, Banco Central de Nicaragua. 
VILLACORTA C., J. Antonio. 1942. Historia de la capitanía general de Guatemala. Guatemala, Tipografía Nacional. 